\title{
To merge or not to merge: That is the question
}

\author{
Luis C. Corchón ${ }^{1}$, Ramon Fauli-Oller ${ }^{2}$ \\ 1 Universidad Carlos III, Departamento de Economía, C/ Madrid 126, 28093 Getafe, Spain \\ (e-mail: 1corchon@eco.uc3m.es) \\ 2 Universitat d'Alacant, Departament Fonaments de l'Anàlisi Econòmica, Campus de Sant Vicent, \\ 03071 Alacant, Spain (e-mail: fauli@ merlin.fae.ua.es)
}

Received: 7 June 2001 / Accepted: 14 June 2004

\begin{abstract}
In this paper we analyze the implementation of socially optimal mergers when the regulator is not informed about all parameters that determine social and private gains from potential mergers. We show that implementation requires a certain degree of agreement between social and private incentives. The most important example where this congruence is present is when the uncertainty refers to cost savings, because in this case society and firms want costs savings to be as high as possible. Then, it is possible to induce firms to truthfully reveal the costs savings induced by the merger.
\end{abstract}

JEL classification: D78, L13, L41

Key words: Merger, antitrust, implementation

\section{Introduction}

Suppose two firms decide to merge. The effects of this merger on social welfare are twofold. On the one hand, the degree of competition falls and this affects social welfare negatively. On the other hand, there might be cost reductions (fixed costs, synergy gains, etc.) or technological improvements that enhance social welfare. The effect that finally dominates depends entirely on the specification of the problem at hand. ${ }^{1}$ It is clear that individual incentives to merge may lead to the wrong decision

This paper was presented at the First CODE meeting held in Barcelona, June 1997 and in seminars at the universities of Alicante, Caen, Carlos III, Bilbao, Complutense (Madrid) and Málaga. We would like to thank P. Amorós, D. Cardona-Coll, P. Hammond, A. Lozano, C. Martinez, V. Merlin, D. Moreno, B. Moreno, D. Mookherjee, J. Naeve, P. Pereira, R. Renault, A. Snoy and F. Vega-Redondo for their useful comments. The authors are solely responsible for any remaining errors. They acknowledge financial support from CICYT BEC2002-02194, PB97-0120, BEC2001-0535 and the IVIE.

1 See Williamson (1968), Salant et al. (1983), Davidson and Deneckere (1985), Perry and Porter (1985), Salop et al. (1987) and Salinger (1988). 
from the point of view of social welfare. That is why, in most western countries, certain mergers have to be submitted for approval by an independent body.

In USA, Merger Guidelines $(M G)$ were jointly issued by the Department of Justice and the Federal Trade Commission (1992, 1997). The MG set "general standards for horizontal mergers" that "affect the degree to which a merger raises competitive concern" (MG, Sect. 1.51). These standards are based on the values of Herfindahl-Hirschmann Index both ex ante and ex post (MG, Sect. 1.5). The Department of Justice has, sometimes, used a more sophisticated technique that requires estimation of the demand curve (Shapiro 1995; Werden 1996). But even if a merger raises competitive concerns, it could be authorized if it increases the productive efficiency of the firms involved (MG Sect. 4). However, MG explicitly recognize the asymmetry of information concerning efficiency gains between firms and agencies in charge of applying these guidelines: "Efficiencies are difficult to verify and quantify, in part because much of the information relating to efficiencies is uniquely in the possession of the merging firms" (MG, Sect. 4).

The theory of implementation deals with the design of mechanisms in which the planner and the agents have different information and objectives and, in order to achieve social objectives, the planner needs information that is possessed by agents. But the information supplied by agents can not be trusted because agents may find it in their interest to submit false information. Thus, the planner is constrained to achieve allocations that are implementable in the sense that agents must have incentives to provide the information needed to achieve these allocations. The theory of implementation provides conditions under which social goals can be implemented or not (an up to date survey is provided by Jackson 2001).

In this paper we apply implementation theory to the problem of finding institutions that control mergers. ${ }^{2}$ The decision on merger can be regarded as a decision at the level of a public good, because merger affects all firms in an industry. This, plus the fact that in our case payoffs (profits) are linear on money suggests that the findings of implementation theory can be applied straightforwardly to the merger problem. However, in the standard model of implementation, the set of agents whose utilities are considered and the set of players who send messages are the same. This is not the case here, because it is not realistic to assume that consumers participate in the process, and thus we have to look for mechanisms in which only firms send messages. This creates a new set up where new techniques and intuitions are needed. We make a first cut to the problem by focussing on the simplest possible case: There are two firms and two market structures, no merger and merger. In the latter Firm 1 buys Firm 2.

Let us summarize the findings of the paper in a nutshell: The possibility of implementing a merger policy depends entirely on a single condition: This condition is sufficient and almost necessary for implementation in dominant strategies of a merger policy if budget balance is not required and sufficient to implement in Nash equilibrium a merger policy with budget balance. Let $P_{1}$ be the difference between monopoly and duopoly profits of Firm 1 . Let $P_{2}$ be duopoly profits of Firm 2.

${ }^{2}$ Besanko and Spulber (1993) studied the game played by the antitrust authority and firms in the case of synergy gains. Farrell and Shapiro (1990) and Levin (1990) provide a rationalization of the procedure proposed by MG. None of these papers use the framework of implementation. 
Let us plot in a diagram all possible values of $P_{1}$ and $P_{2}$ that are a priori possible from the point of view of the planner. These values reflect changes in the demand function, or in the possible efficiency gains should the merger take place, etc. Let $M$ (respectively $N M)$ be the set of points in the plane $\left(P_{1}, P_{2}\right)$ for which merger (resp. no merger) is socially optimal. Then, the condition is the following: It is possible to draw an increasing function such that all the points in $M$ (resp. NM) lie above (respectively below) this function.

The intuition of the above result is that implementation requires a certain degree of congruence between private incentives and social goals. Thus, suppose that the merger increases social welfare in situation A and lowers it in B. The condition requires that at least one of the firms gains more with the merger in $\mathrm{A}$ than in $\mathrm{B}$. To illustrate the issue, we present two examples: one in which implementation is possible and the other where it is not.

Assume that the planner does not know the marginal cost after merger. On the one hand, we have that social welfare associated to merger is higher the lower the marginal cost is. On the other hand, the private gains of Firm 1 when the merger takes place are also decreasing in the postmerger marginal cost. Thus, in this case, private and social gains move in the same direction and therefore the condition is satisfied.

Assume that the planner does not know the productive capacity and firms are identical; The greater the capacity is, the greater the social loss of the merger. However, in this case, private gains move in the opposite direction: As far as Firm 1 is concerned, if capacities are high, the anticompetitive effect is high and therefore the positive effect on profits is also high. As far as Firm 2 is concerned, if capacities are high, profits in duopoly are low and therefore few profits are forgone with the merger. Thus, private and social gains move in opposite directions and the condition does not hold.

Summing up, our approach shows that the informational burden on the agency regulating mergers could be alleviated by the use of implementation theory and that implementation of the socially optimal merger policy is sometimes possible. We give several examples of this. However, we are aware that procedures considered here are too stylized and refer to the simplest case of merger. Our paper simply wants to indicate a new direction which might be worth looking at. Some extensions of our model are discussed in the last section.

\section{The model}

We assume two firms, Firm 1 and Firm 2, and two possible market structures merger because Firm 1 buys Firm 2 (denoted by $a_{1}$ ) and no merger (denoted by $a_{2}$ ). This simplification is justified since it is the simplest possible form of merger. If in this case the efficient merger policy can not be implemented, there is no hope that this could be done in more complicated cases. If it can, we may hope to obtain insights that may be useful to deal with the general case. Let $A=\left\{a_{1}, a_{2}\right\}$. The type of firm $i$, denoted by $\theta_{i}$, is a description of all relevant characteristics (costs, demand, price of inputs, etc.) before and after any possible merger regarding firm $i$. Let $\Theta_{i}$ be the set of all possible characteristics of firm $i$. Let $\Theta=X_{i=1}^{2} \Theta_{i}$, be the 
set of characteristics with typical element $\theta$ (most of our results do not need the Condition that $\Theta$ has Cartesian product structure). We now spell out two special instances of our problem that will be used in the sequel.

Rationalization. Firm 1 and Firm 2 have average $\operatorname{cost} c_{1}$ and $c_{2}$ respectively. It is known that $c_{1} \leq c_{2}$, but their actual values are unknown. The merger allows to transfer production from the high cost to the low cost firm.

Synergy gains. Firm 1 and Firm 2 produce with average cost $c$. If both firms merge, average cost will be $d<c$. $d$ and $c$ are unknown to the regulator.

The merger decisions involve transfers of money among firms. Let $t_{i}$ be the transfer of money to player $i$. Typically, if firm $i$ is bought during the merger stage, $t_{i}$ will be positive. We assume that once the merger decision has been taken, the remaining firms engage in some form of competition (Cournot, Bertrand, etc.). We represent this in reduced form by writing $\Pi_{i}(a, \theta)$ as the expected payoffs of $i$ as a function of market structure $(a)$ and characteristics of all firms $(\theta){ }^{3}$ Notice that in general the payoff of firm $i$ depends on the characteristics of all firms. In the context of Bayesian games this situation is called common values. The case in which the payoff of firm $i$ depends only on the characteristic of $i$ is called private values (see e.g. Fudenberg and Tirole 1991, pp. 297-298). An example of the latter is when characteristics of firms are fixed costs provided that they are such that all firms are always active. If firm $i$ is bought during the merger stage $\Pi_{i}(a, \theta)=0$. Thus, the payoff function of firm $i$ is $\Pi_{i}(a, \theta)+t_{i}$ also written as $V_{i}\left(a, \theta, t_{i}\right)$.

We assume that the regulator has no power whatsoever to interfere with the nature of competition, once merger decisions have been taken. ${ }^{4}$ In this sense we focus on structure regulation and not on conduct regulation (Vickers 1995). However the regulator can enforce the rules under which mergers and transfers take place by means of a mechanism $\left\{M_{i}, g\right\}_{i=1,2}$ where $M_{i}$ is the set of all possible messages sent by $i$, with typical element $m_{i}$. In this paper we disregard consumers as a source of information, either because they are not informed about costs, technology, etc., or because it is too costly to ask each consumer about her own characteristic. In fact we assume that such characteristics are known by firms (as it is implicitly assumed by Cournot and Bertrand equilibria). See Examples 3 and 4 below.

Therefore we will consider mechanisms in which only firms send messages. Let $m \in M \equiv X_{i=1}^{2} M_{i}$ be a list of messages. $g=\left(h(), t_{1}(), t_{2}()\right)$ is the outcome function where $h: M \longrightarrow A$ decides mergers as a function of messages and $t_{i}$ : $M \longrightarrow R, i=1,2$ decides the payment received by firm $i$. We assume that all payments are controlled by the regulator. If $\sum_{i=1}^{2} t_{i}(m) \leq 0$ for any $m \in M$ the mechanism is feasible. If, in addition $\sum_{i=1}^{2} t_{i}(m *)=0$ when $m *$ is an equilibrium message, the mechanism is budget balanced.

\footnotetext{
${ }^{3}$ If there are several equilibria we assume that each firm has a subjective probability distribution on the occurrence of different equilibria and so $\Pi_{i}()$ represents expected profits.

${ }^{4}$ In other words, the information gathered from the mechanism can not be used later on to regulate firms. This may be due to several reasons. For instance in the implementing mechanism presented in Proposition 2 below, the messages do not permit the complete identification of characteristics. Or, if such identification is possible, output and profits might be not contractible, an assumption that is plausible for mergers in certain sectors like banks or airlines.
} 
If the regulator had complete information, she would like to allow certain mergers and to forbid others depending on the characteristics of firms. Let $\phi: \Theta \longrightarrow A$ represent the optimal structure of mergers as a function of the characteristics of firms. This function is called a Social Choice Rule (SCR). In what follows we will be mostly concerned with a specific SCR: Let the consumer surplus be written as $C S(a, \theta)$. The social welfare, denoted by $W$, is defined as $\sum_{i=1}^{2} \Pi_{i}(a, \theta)+C S(a, \theta) \equiv W(a, \theta)$. Then, the efficient merger policy $\phi^{\circ}$ is defined as follows; $\phi^{o}(\theta)=\arg \max _{a \in A} W(a, \theta)$. An extended SCR $\phi: \Theta \longrightarrow A \times R^{2}$ maps the characteristics of firms into the decision on mergers and transfers.

A strategy for $i$ is a mapping $s_{i}: \Theta \rightarrow M_{i}$.

A mechanism $\left\{M_{i}, g\right\}_{i=1 \ldots 2}$ implements the extended SCR $\phi$ in dominant strategies if there are strategies $\left(s_{1}(), s_{2}()\right)=s()$ such that:

a) $g(s(\theta))=\phi(\theta)$ for all $\theta \in \Theta$. And

b) $V_{i}\left(g\left(s_{i}(\theta), m_{-i}\right), \theta\right) \geq V_{i}\left(g\left(m_{i}, m_{-i}\right), \theta\right)$ for all $\left(m_{i}, m_{-i}\right) \in M$, and $\theta \in \Theta$.

A mechanism $\left\{M_{i}, g\right\}_{i=1 \ldots 2}$ implements the extended SCR $\phi$ in Nash equilibrium if there are strategies $\left(s_{1}(), s_{2}()\right)=s()$ such that:

a) $g(s(\theta))=\phi(\theta)$ for all $\theta \in \Theta$.And

b) $V_{i}\left(g\left(s_{i}(\theta), s_{-i}(\theta)\right), \theta\right) \geq V_{i}\left(g\left(m_{i}, s_{-i}(\theta)\right), \theta\right)$ for all $m_{i} \in M_{i}$ and $\theta \in \Theta$.

\section{Dominant strategies}

Prima facie, our problem is similar to the problem of implementing an efficient SCR with quasi-linear utility functions, one public good (the merger decision) and one private good (transfers). In these economies, the Vickrey-Clarke-Groves mechanism is such that announcing the true characteristics is a dominant strategy for each agent, and the decision regarding the public good is efficient (Vickrey 1961; Clarke 1971; Groves 1973). This mechanism does not achieve budget balance in general. ${ }^{5}$ However, there is an important difference between our setting and the one where the Vickrey-Clarke-Groves mechanism works successfully. In our case, the welfare of consumers enters the social surplus, but they do not send messages. Thus, new tools are needed. ${ }^{6}$

It is helpful to define the change in welfare and profits induced by the monopolization of the industry. The change in welfare in economy $\theta$ is given by:

$$
\Delta W \equiv W\left(a_{1}, \theta\right)-W\left(a_{2}, \theta\right)
$$

\footnotetext{
5 Moreover, any mechanism attaining efficient decision on the public good must be a VickreyClarke-Groves mechanism (Green and Laffont 1979). Thus, in general, it is not possible to implement in dominant strategies any efficient and individually rational SCR. See Groves and Loeb (1975) for a case where implementation is possible.

${ }^{6}$ In Appendix A we show that if consumers knew the state of the economy and participate in the mechanism, implementation of the eficient merger policy is possible using a generalization of the Vickrey-Clarke-Groves mechanism
} 


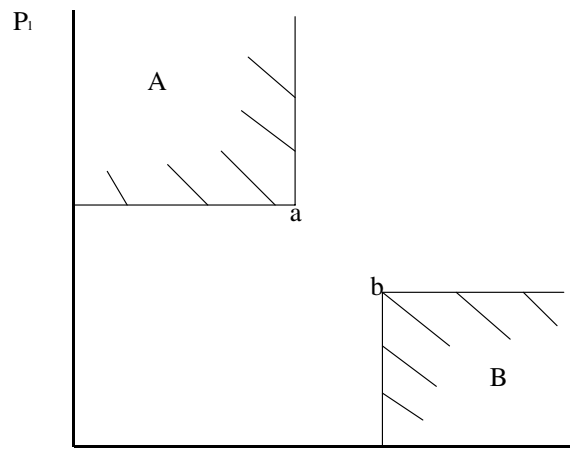

$\mathrm{P}_{2}$

Fig. 1.

The change in profits of Firm 1 is given by:

$$
P_{1} \equiv \Pi_{1}\left(a_{1}, \theta\right)-\Pi_{1}\left(a_{2}, \theta\right)
$$

The relevant information as far as Firm 2 is concerned is its duopoly profits i.e. what he loses with the merger. They are defined accordingly as:

$$
P_{2} \equiv \Pi_{2}\left(a_{2}, \theta\right)
$$

$P_{2}$ can be interpreted as the minimum price that induces Firm 2 to sell and of $P_{1}$ as the maximum price that Firm 1 is prepared to pay for the acquisition of Firm 2. When needed, $\Delta W, P_{1}$ and $P_{2}$ will be written as a function of the underlying characteristic $\theta$ as $\Delta W(\theta), P_{1}(\theta)$ and $P_{2}(\theta)$.

Let us first concentrate on necessary conditions of implementation by mechanisms in which truth is a dominant strategy. This procedure is validated by the Revelation Principle. Consider the following condition:

Condition $N$. Let $\theta^{1}, \theta^{2} \in \Theta$. Then if $\Delta W\left(\theta^{1}\right)>0 \geq \Delta W\left(\theta^{2}\right)$ then:

$$
\text { either } P_{1}\left(\theta^{1}\right) \geq P_{1}\left(\theta^{2}\right) \text { or } P_{2}\left(\theta^{2}\right) \geq P_{2}\left(\theta^{1}\right) \text {. }
$$

Condition $\mathrm{N}$ states that if a merger is socially optimal in $\theta$, in any $\theta^{\prime}$ with $P_{1}\left(\theta^{\prime}\right)>$ $P_{1}(\theta)$ and $P_{2}\left(\theta^{\prime}\right)<P_{2}(\theta)$, merger has to be socially optimal. Conversely, if no merger is socially optimal in $\theta$, in any $\theta^{\prime}$ with $P_{1}\left(\theta^{\prime}\right)<P_{1}(\theta)$ and $P_{2}\left(\theta^{\prime}\right)>P_{2}(\theta)$ merger can not be socially optimal. In Fig. 1, if at point $a$ merger is socially optimal, merger must be socially optimal at any point in A. Conversely, if at point $b$ no merger is socially optimal, no merger must be optimal for any point in B.

Proposition 1. If a SCR is implementable in Dominant Strategies, condition N holds. 
The intuition behind Proposition 1 is that implementation requires a certain degree of congruence between social and private incentives. When society gains more when the merger takes place in $\theta^{1}$ than in $\theta^{2}$, there should be at least one firm that gains more with the merger in $\theta^{1}$ than in $\theta^{2}$. (For Firm 2 it would be more appropriate to say that it loses less with the merger in $\theta^{1}$ than in $\theta^{2}$ ). When private incentives move in the opposite direction as social incentives, implementation becomes impossible.

We now present two examples and see how Condition $\mathrm{N}$ looks like.

Example 1. Uncertainty about fixed costs. f The effect on consumer surplus of a merger is constant and we denote it by $\nabla C S$. Assume that in economy $\theta^{1}$ the merger increases welfare and in economy $\theta^{2}$ it reduces welfare. The change in welfare due to monopolization can be written in each case as:

$$
\begin{aligned}
& \Delta W\left(\theta^{1}\right)=P_{1}\left(\theta^{1}\right)-P_{2}\left(\theta^{1}\right)-\nabla C S>0 \\
& \Delta W\left(\theta^{2}\right)=P_{1}\left(\theta^{2}\right)-P_{2}\left(\theta^{2}\right)-\nabla C S<0
\end{aligned}
$$

Subtracting (3.2) from (3.1) we have:

$$
\left[P_{1}\left(\theta^{1}\right)-P_{1}\left(\theta^{2}\right)\right]+\left[P_{2}\left(\theta^{2}\right)-P_{2}\left(\theta^{1}\right)\right]>0
$$

This implies that the necessary condition is satisfied. In this case, firms fully internalize the benefits of the merger i.e. the possible reduction in fixed costs. Then, social incentives move in the same direction as private incentives and condition $\mathrm{N}$ is satisfied.

Example 2. Uncertainty on capacities.

Market demand is given by $P=100-q$, where $P$ denotes price and $q$ quantity. The marginal costs of the firms are known. In duopoly, each firm has a marginal cost 10 . In monopoly the firm produces at marginal cost 5 . In economy $\theta^{1}$, each firm has a capacity $k_{1}=\frac{95}{4}$ and in economy $\theta^{2}$ each firm has a capacity $k_{2}=30$. The production capacity of the monopoly is $2 k_{i}$. Then it is easy to verify that:

$$
\Delta W\left(\theta^{1}\right)>0>\Delta W\left(\theta^{2}\right)
$$

But that

$$
P_{1}\left(\theta^{1}\right)<P_{1}\left(\theta^{2}\right) \text { and } P_{2}\left(\theta^{2}\right)<P_{2}\left(\theta^{1}\right) .
$$

Society wants the merger to occur when capacities are low because then its anticompetitive effect is also low. On the contrary, firms prefer the merger when capacities are high for exactly the same reason. Thus, condition $\mathrm{N}$ fails here.

We now look for a sufficient condition that allows the implementation of the efficient merger policy in dominant strategies. Let $D$ be the set of possible values taken by $P_{2}$ and $E$ the set of possible values taken by $P_{1}$. Consider now the following condition. 
Condition $S$. There is a strictly increasing and onto function $f: D \longrightarrow E$ such that

$$
\Delta W>0 \text { iff } P_{1}>f\left(P_{2}\right) .
$$

Condition $\mathrm{S}$ says that the $D x E$ plane can be split by an increasing function such that if a point is above (respectively below) this function, merger is socially optimal (respectively not socially optimal). Notice that condition $\mathrm{S}$ implies condition $\mathrm{N}$. The only divergence between both conditions appears when the boundary of the merger and the no-merger zones includes a flat step, a possibility that is not excluded by $\mathrm{N}$. Then, a strictly increasing function can not do the job of partitioning both regions. In any case, notice that $\mathrm{N}$ requires that the function partitioning the merger and the no-merger zones is not decreasing. Thus, if this function is never constant, as happens in Example 1 above and Examples 3 to 5 below, conditions $\mathrm{N}$ and $\mathrm{S}$ are identical because in this case condition $\mathrm{N}$ amounts to require the existence of a strictly increasing function.

We now spell out several examples in which Condition $\mathrm{S}$ holds. We will assume that $D=E=\mathcal{R}_{+}$.

Example 3. Uncertainty on synergy gains and demand.

Firms produce differentiated goods whose inverse demand functions are:

$$
p_{i}=a-X_{i}-b X_{j}, i, j=1,2, i \neq j=1,2 .
$$

where $a>0$ and $b \in[0,1]$. These demands are derived from the maximization problem of a representative consumer (see Singh and Vives 1984) endowed with a consumer surplus of the following form

$$
a\left(X_{1}+X_{2}\right)-\frac{X_{1}^{2}}{2}-\frac{X_{2}^{2}}{2}-b X_{1} X_{2}
$$

Both firms produce premerger at unit cost $c$. The unit cost postmerger is $d$. Parameters $a, c$ and $d$ are unknown to the planner.

Condition $\mathrm{S}$ holds because with Cournot competition $\Delta W>0$ iff $P_{1}>$ $P_{2}\left(\frac{3+2 b}{3}\right)$ and with Bertrand competition $\Delta W>0$ iff $P_{1}>P_{2}\left(\frac{3-b}{3(1-b)}\right)$ (see Appendix C). With homogenous goods, Condition $\mathrm{S}$ holds for general demands satisfying the standard stability condition (see Appendix D).

Example 4. Uncertainty on the degree of product differentiation.

We consider a market with two differentiated goods with demand functions as in (3.3) and Cournot competition. In this case $a$ is known and costs both premerger $(c)$ and postmerger $(d)$ are also known. The unknown parameter refers to the degree of product differentiation $b$. Condition $\mathrm{S}$ holds because $\Delta W>0$ iff $P_{1}>f\left(P_{2}\right)$ where $f\left(P_{2}\right)=\left(\frac{2}{3}\right)\left((a-c) \sqrt{P_{2}}-\frac{P_{2}}{2}\right)$ (see Appendix C).

Example 5. Uncertainty on the degree of rationalization.

We consider a market with two differentiated goods with the same demands as in (3.3). To keep expressions tractable we assume $b=\frac{1}{2}$. We have two firms 


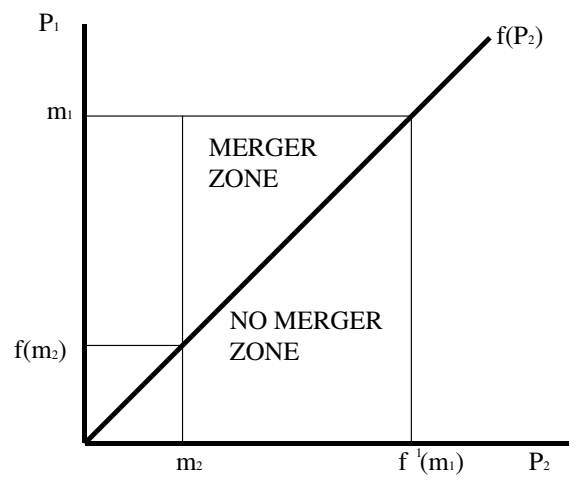

Fig. 2.

competing with average cost $\mathrm{c}_{1}$ and $\mathrm{c}_{2}\left(\mathrm{c}_{1} \leq \mathrm{c}_{2}\right)$ respectively. The planner must decide whether to approve the takeover of the inefficient firm by the efficient firm. Parameters $a, c_{1}$ and $c_{2}$ are unknown to the planner. Condition $\mathrm{S}$ holds because with Cournot competition $\Delta W>0$ iff $P_{1}>P_{2}\left(\frac{5+2 \sqrt{3}}{6}\right)$ and with Bertrand competition because $\Delta W>0$ iff $P_{1}>P_{2}\left(\frac{2(55+8 \sqrt{10})}{81}\right)$ (see Appendix E).

We now present our main result in this section.

Proposition 2. Under Condition S, the efficient merger policy can be implemented in dominant strategies by the following mechanism: The buyer announces $m_{1} \in E$ and the seller announces $m_{2} \in D$. If $m_{1} \leq f\left(m_{2}\right)$, the merger is not allowed. If $m_{1}>f\left(m_{2}\right)$, the merger takes place and the buyer pays $f\left(m_{2}\right)$ and the seller receives $f^{-1}\left(m_{1}\right)$.

Proof. The mechanism yields the efficient merger policy if players tell the truth. We show that the truth is a dominant strategy for the buyer. Denote by $P_{1}^{o}$ the true value of $P_{1}$. If $P_{1}^{o}>f\left(m_{2}\right)$, the buyer is better-off with the merger and this is obtained simply by telling the truth. If $P_{1}^{o} \leq f\left(m_{2}\right)$, the buyer is better-off without the merger and this is obtained by telling the truth.

We show that the truth is a dominant strategy for the seller. Given that $f\left(P_{2}\right)$ is strictly increasing we have that $\Delta W>0$ iff $f^{-1}\left(P_{1}\right)>P_{2}$. Denote by $P_{2}^{o}$ the true value of $P_{2}$. If $f^{-1}\left(m_{1}\right)>P_{2}^{o}$, the seller is better-off with the merger and this is obtained simply by telling the truth. If $f^{-1}\left(m_{1}\right) \leq P_{2}^{o}$, the seller is better-off without the merger and this is obtained by telling the truth.

Figure 2 illustrates the working of the implementing mechanism. Given the messages sent by firms $\left(m_{1}, m_{2}\right)$, the mechanism stipulates merger because $m_{1}>$ $f\left(m_{2}\right)$. Furthermore Firm 1 pays $f\left(m_{2}\right)$ and firm 2 receives $f^{-1}\left(m_{1}\right)$. Figure 2 clearly reveals that the mechanism does not satisfy budget balance.

Our mechanism has some resemblance to the pivotal mechanism (Clarke 1971; Groves 1973). In this mechanism (and in ours) an agent's payment is independent of her announcement unless it changes the level of the public good (the merger decision in our case). In our case we need the function $f$ to signal if those changes are welfare 
enhancing or not. This is not needed in the pivotal mechanism because social welfare equals the sum of the utilities of the agents involved in the game. Notice that if a firm tells the truth, it obtains payoffs larger or equal than those that can be obtained under duopoly. In other words our mechanism is individually rational. Unfortunately, our mechanism is not feasible because in general $f\left(m_{2}\right) \neq f^{-1}\left(m_{1}\right)$.

\section{Nash implementation}

The positive results obtained in the previous section depended on the fact that the mechanism was not feasible. In this section we consider an equilibrium concept weaker than dominant strategies, namely Nash equilibrium. We will see that if Condition S does not hold, the efficient merger policy can not be implemented with budget balance in Nash equilibrium. Moreover, under Condition S the efficient merger policy can be implemented in Nash Equilibrium with budget balance. We therefore have a trade-off regarding the implementation of efficient mergers: Implementation without budget balance is possible in dominant strategies (a very robust equilibrium concept), and implementation with budget balance is possible in Nash equilibrium (a not so appealing equilibrium concept).

Since the emphasis of this section is on budget balance, it is important to specify the transfers associated with the efficient merger policy. We will assume that in the case of no merger these transfers are zero and in the case of merger, they are any transfers that make merger individually rational. If the merger occurs, the transfer is the acquisition price.

We now invoke a result by Moore and Repullo (1990, p. 1094) on the implementation of (in our terminology) extended SCR with two agents:

Theorem 1. If a two agent extended SCR $\Phi$ satisfies monotonicity and restricted veto power and there is a bad outcome, then $\Phi$ can be implemented in Nash equilibrium with budget balance.

Rather than giving formal definitions of these terms (which may be found in the original paper) we will give literary (but we hope precise) descriptions of the conditions of the above theorem.

Restricted Veto Power (RVP). Suppose outcome $a$ is top ranked under $\theta$ by firm $j$ and there is an outcome $b$ in the range of $\Phi$ such that under $\theta$, the other firm $i$ weakly prefers $a$ to $b$. Then $a$ must be selected by $\Phi$ under $\theta$.

Bad Outcome $(B O)$. $z$ is a bad outcome if for any $\theta, z$ is strictly worse for both agents than any outcome in the range of $\Phi$.

Monotonicity $(M)$. Suppose outcome $z$ is selected by $\Phi$ under characteristic $\theta$. Consider a new characteristic $\theta^{\prime}$ such that $z$ goes up (or remains constant) in the preferences of all firms. Then $z$ should be selected by $\Phi$ under $\theta^{\prime}$.

Given an outcome $z_{1}=\left(a_{1}, \bar{t}_{1}, \bar{t}_{2}\right)$ we can define the set of allocations preferred to $z_{1}$ by firms 1 and 2 given $\theta$ respectively as:

$$
\begin{aligned}
& U_{1}\left(z_{1}, \theta\right)=\left\{\left(a_{1}, t_{1}, t_{2}\right) / t_{1} \geq \bar{t}_{1}\right\} \cup\left\{\left(a_{2}, t_{1}, t_{2}\right) / t_{1} \geq \bar{t}_{1}+P_{1}(\theta)\right\} \\
& U_{2}\left(z_{1}, \theta\right)=\left\{\left(a_{1}, t_{1}, t_{2}\right) / t_{2} \geq \bar{t}_{2}\right\} \cup\left\{\left(a_{2}, t_{1}, t_{2}\right) / t_{2} \geq \bar{t}_{1}-P_{2}(\theta)\right\}
\end{aligned}
$$


If given a state of the world $\theta^{\prime}$ we have that

$$
U_{i}\left(z_{1}, \theta^{\prime}\right) \subseteq U_{i}\left(z_{1}, \theta\right) \quad i=1,2
$$

we say that $z_{1}$ goes up in the preferences of all firms or that the upper contour sets shrink. (4.1) holds if:

$$
P_{1}\left(\theta^{\prime}\right) \geq P_{1}(\theta) \text { and } P_{2}\left(\theta^{\prime}\right) \leq P_{2}(\theta)
$$

Similarly given an outcome $z_{2}=\left(a_{2}, t_{1}, t_{2}\right)$ we have that

$$
\begin{aligned}
& U_{1}\left(z_{2}, \theta\right)=\left\{\left(a_{2}, t_{1}, t_{2}\right) / t_{1} \geq \bar{t}_{1}\right\} \cup\left\{\left(a_{1}, t_{1}, t_{2}\right) / t_{1} \geq \bar{t}_{1}-P_{1}(\theta)\right\} \\
& U_{2}\left(z_{2}, \theta\right)=\left\{\left(a_{2}, t_{1}, t_{2}\right) / t_{2} \geq \bar{t}_{2}\right\} \cup\left\{\left(a_{1}, t_{1}, t_{2}\right) / t_{2} \geq \bar{t}_{1}+P_{2}(\theta)\right\}
\end{aligned}
$$

Then,

$$
U_{i}\left(z_{2}, \theta^{\prime}\right) \subseteq U_{i}\left(z_{2}, \theta\right) \quad i=1,2
$$

if

$$
P_{1}\left(\theta^{\prime}\right) \leq P_{1}(\theta) \text { and } P_{2}\left(\theta^{\prime}\right) \geq P_{2}(\theta)
$$

Clearly, RVP and BO hold in our framework: If the maximum amount of negative transfers is large enough, the top ranked outcome of, say, Firm 1 involves such a large transfer that the other firm will prefer any outcome in $\Phi$ to this situation. The bad outcome can be constructed by imposing very large negative transfers to both firms. Also, by a theorem of Maskin (see e.g. Moore and Repullo 1990, p. 1087), a Nash implementable SCR must be monotonic. Thus, the efficient merger policy can be implemented in Nash equilibrium if and only if monotonicity holds. Unfortunately, monotonicity does not always hold in our framework:

Proposition 3. Monotonicity does not hold in every possible domain.

Proof. Consider again Example 2. In the state of the world $\theta^{1}$ merger is the socially optimal alternative. Consider now indifference curves in state $\theta^{2}$. It is the case that $P_{2}\left(\theta^{2}\right)<P_{2}\left(\theta^{1}\right)$ and $P_{1}\left(\theta^{2}\right)>P_{1}\left(\theta^{1}\right)$. Thus when we go from $\theta^{1}$ to $\theta^{2}$ the point selected by the efficient merger policy and the corresponding transfers go up in the preferences of both firms. However, as we saw before, the merger is not socially optimal at $\theta^{2}$.

Proposition 3 implies that the efficient merger policy can not be implemented in Nash equilibrium in unrestricted environments. Nevertheless, if Condition S holds, implementation becomes possible.

Proposition 4. If Condition S holds, then the efficient merger is implementable in Nash equilibrium with budget balance.

Proof. We have demonstrated before that RVP and BO hold in our framework. 
Theorem 1. Then by Theorem 4.1. we only have to show that Monotonicity holds to prove Nash implementation.

Given economy $\theta^{1}$ we may have that the merger either increases welfare

$$
\Delta W\left(\theta^{1}\right)>0
$$

or that the merger reduces welfare:

$$
\Delta W\left(\theta^{1}\right) \leq 0
$$

Suppose that (4.2) holds. That upper contour sets shrink is equivalent to:

$$
P_{2}\left(\theta^{1}\right) \geq P_{2}\left(\theta^{2}\right) \text { and } P_{1}\left(\theta^{1}\right) \leq P_{1}\left(\theta^{2}\right) .
$$

Condition S and (4.2) imply:

$$
f\left(P_{2}\left(\theta^{1}\right)\right)<P_{1}\left(\theta^{1}\right) .
$$

Using (4.4), we have:

$$
f\left(P_{2}\left(\theta^{2}\right)\right) \leq f\left(P_{2}\left(\theta^{1}\right)\right)<P_{1}\left(\theta^{1}\right) \leq P_{1}\left(\theta^{2}\right) .
$$

which implies, if Condition $\mathrm{S}$ is satisfied, that

$$
\Delta W\left(\theta^{2}\right)>0 .
$$

And this is what is implied by Monotonicity.

Suppose now that (4.3) holds. That upper contour sets shrink is equivalent to:

$$
P_{2}\left(\theta^{1}\right) \leq P_{2}\left(\theta^{2}\right) \text { and } P_{1}\left(\theta^{1}\right) \geq P_{1}\left(\theta^{2}\right)
$$

Condition S and (4.3) imply

$$
f\left(P_{2}\left(\theta^{1}\right)\right) \geq P_{1}\left(\theta^{1}\right)
$$

Using (4.5) we have:

$$
f\left(P_{2}\left(\theta^{2}\right)\right) \geq f\left(P_{2}\left(\theta^{1}\right)\right) \geq P_{1}\left(\theta^{1}\right) \geq P_{1}\left(\theta^{2}\right) .
$$

which implies if Condition $\mathrm{S}$ is satisfied, that

$$
\Delta W\left(\theta^{2}\right) \leq 0
$$

And this is what is implied by Monotonicity. 
Table 1. Economy $\theta^{1}$

\begin{tabular}{cccc}
\hline \multicolumn{4}{c}{ Firm 2 } \\
& $\theta_{2}^{1}$ & $\theta_{2}^{2}$ & \\
\hline Firm & $\theta_{1}^{1}$ & $\Pi_{1}\left(a_{1}, \theta^{1}\right)-T, T$ & $\Pi_{1}\left(a_{1}, \theta^{1}\right)-S, S$ \\
1 & $\theta_{1}^{2}$ & $\Pi_{1}\left(a_{2}, \theta^{1}\right), \Pi_{2}\left(a_{2}, \theta^{1}\right)-P$ & $\Pi_{1}\left(a_{2}, \theta^{1}\right), \Pi_{2}\left(a_{1}, \theta^{1}\right)$ \\
\hline
\end{tabular}

Table 2. Economy $\theta^{2}$

\begin{tabular}{cccc}
\hline & & Firm 2 & $\theta_{2}^{1}$ \\
& & $\theta_{2}^{2}$ \\
\hline Firm & $\theta_{1}^{1}$ & $\Pi_{1}\left(a_{1}, \theta^{2}\right)-T, T$ & $\Pi_{1}\left(a_{1}, \theta^{2}\right)-S, S$ \\
1 & $\theta_{1}^{2}$ & $\Pi_{1}\left(a_{2}, \theta^{2}\right), \Pi_{2}\left(a_{2}, \theta^{2}\right)-P$ & $\Pi_{1}\left(a_{2}, \theta^{2}\right), \Pi_{2}\left(a_{2}, \theta^{2}\right)$ \\
\hline
\end{tabular}

Finally we remark that the converse of Proposition 4 is not true, i.e. monotonicity does not imply Condition S. Suppose that $D=E=[1,2]$ and that merging is always the socially optimal alternative. The function required by Condition $\mathrm{S}$ obviously does not exist, but the efficient merger policy is trivially implementable in Nash equilibrium by a mechanism in which any message sent by the firms yields the alternative "merge". Thus, this SCR must be monotonic, but it does not satisfy Condition S.

We end this section by showing the implementing mechanism for a simple case. There are only two possible economies, denoted by $\theta^{1}$ and $\theta^{2}$ such that $\phi^{o}\left(\theta^{1}\right)=a_{1}$ and $\phi^{o}\left(\theta^{2}\right)=a_{2}$. Let $\theta_{i}^{j}$ denote the announcement of economy $\theta^{j}$ by firm $i$. Condition $S$ reads,

$$
P_{1}\left(\theta^{1}\right)=\Pi_{1}\left(a_{1}, \theta^{1}\right)-\Pi_{1}\left(a_{2}, \theta^{1}\right)>P_{1}\left(\theta^{2}\right)=\Pi_{1}\left(a_{1}, \theta^{2}\right)-\Pi_{1}\left(a_{2}, \theta^{2}\right)
$$

or

$$
P_{2}\left(\theta^{2}\right)=\Pi_{2}\left(a_{2}, \theta^{2}\right)>P_{2}\left(\theta^{1}\right)=\Pi_{2}\left(a_{2}, \theta^{1}\right) .
$$

If (4.6) holds, the implementing mechanism is based on two numbers $T$ and $S$ that satisfy

$$
\Pi_{1}\left(a_{1}, \theta^{1}\right)-\Pi_{1}\left(a_{2}, \theta^{1}\right)>T>S>\Pi_{1}\left(a_{1}, \theta^{2}\right)-\Pi_{1}\left(a_{2}, \theta^{2}\right) .
$$

The implementing mechanism specifies merger whenever $\theta_{1}^{1}$ is announced and no merger otherwise. When a merger takes place and $\theta_{2}^{1}$ (resp. $\left.\theta_{2}^{2}\right)$ is announced Firm 1 pays $T(S)$ and Firm 2 receives $T(S)$. No other transfer is considered except when the announcement is $\left(\theta_{1}^{2}, \theta_{2}^{1}\right)$ that Firm 2 pays an exogenous fine $P>0$. Observe that in this case the budget is not balanced outside equilibrium, but we are only requiring that budget balance holds in equilibrium. This will be satisfied if truth telling is the only Nash equilibrium of the announcement game. To see this we write down the payoff matrix of this game in economy $\theta^{1}$ and in economy $\theta^{2}$ (Tables 1 and 2). 
Table 3. Economy $\theta^{1}$

\begin{tabular}{cccc}
\hline & \multicolumn{2}{c}{ Firm 2 } \\
& & $\theta_{2}^{1}$ & $\theta_{2}^{2}$ \\
\hline Firm & $\theta_{1}^{1}$ & $\Pi_{1}\left(a_{1}, \theta^{1}\right)-T, T$ & $\Pi_{1}\left(a_{2}, \theta^{1}\right)-P, \Pi_{2}\left(a_{2}, \theta^{1}\right)$ \\
1 & $\theta_{1}^{2}$ & $\Pi_{1}\left(a_{1}, \theta^{1}\right)-S, S$ & $\Pi_{1}\left(a_{2}, \theta^{1}\right), \Pi_{2}\left(a_{1}, \theta^{1}\right)$ \\
\hline
\end{tabular}

Table 4. Economy $\theta^{2}$

\begin{tabular}{cccc}
\hline & \multicolumn{2}{c}{ Firm 2 } \\
& & $\theta_{2}^{1}$ & $\theta_{2}^{2}$ \\
\hline Firm & $\theta_{1}^{1}$ & $\Pi_{1}\left(a_{1}, \theta^{2}\right)-T, T$ & $\Pi_{1}\left(a_{2}, \theta^{2}\right)-P, \Pi_{2}\left(a_{2}, \theta^{2}\right)$ \\
1 & $\theta_{1}^{2}$ & $\Pi_{1}\left(a_{1}, \theta^{2}\right)-S, S$ & $\Pi_{1}\left(a_{2}, \theta^{2}\right), \Pi_{2}\left(a_{1}, \theta^{2}\right)$ \\
\hline
\end{tabular}

To see that, in each economy, telling the truth is the only Nash equilibrium observe that for Firm 1 telling the truth is a strictly dominant strategy and given that Firm 1 tells the truth the best response for Firm 2 is also to tell the truth.

If (4.7) holds, the implementing mechanism is based on two numbers $T$ and $S$ that satisfy

$$
\Pi_{2}\left(a_{2}, \theta^{2}\right)>S>T>\Pi_{2}\left(a_{2}, \theta^{1}\right)
$$

The implementing mechanism specifies merger whenever $\theta_{2}^{1}$ is announced and no merger otherwise. When a merger takes place and $\theta_{1}^{1}\left(\right.$ resp. $\left.\theta_{1}^{2}\right)$ is announced Firm 1 pays $T(S)$ and Firm 2 receives $T(S)$. No other transfer is considered except when the announcement is $\left(\theta_{1}^{1}, \theta_{2}^{2}\right)$ that Firm 1 pays an exogenous fine $P>0$. Observe that if firms tell the truth the mechanism implements in budget balance. To see that truth telling is the only Nash equilibrium we write down the payoff matrix of the announcement game played by firms in economy $\theta^{1}$ and in economy $\theta^{2}$ (Tables 3 and 4).

To see that, in each economy, telling the truth is the only Nash equilibrium observe that for Firm 2 telling the truth is a strictly dominant strategy and given that Firm 2 tells the truth the best response for Firm 1 is also to tell the truth.

\section{Conclusions}

In this paper we study the design of mechanisms that implement the efficient merger policy in dominant strategies and in Nash equilibrium. The main departure of our approach with the standard theory is that in our model, not all agents send messages. We can call this, paternalistic implementation.

In our case Condition $S$ is the key that allows us to implement the efficient merger policy without budget balance in dominant strategies, and with budget balance in Nash equilibrium. We have seen that this condition is satisfied in some standard models used in Industrial Organization. 
There are several extensions of our paper that are worth mentioning.

On the one hand, other solution concepts might be considered: i) We know that any SCR is implementable in Subgame Perfect Nash equilibrium in quasi-linear environments (Moore and Repullo 1988). We do not know if a similar result would hold in our framework. ii) It will be interesting to consider that firms have asymmetric information, and to cast the merger problem in the framework of Bayesian implementation with common values, see, e.g. Dasgupta and Maskin (2000) and Jehiel and Moldovanu (2001). iii) The problem of coalition formation must be addressed. We suspect that implementation of the efficient merger policy is not possible under concepts like strong equilibrium.

On the other hand, we might consider more complex situations such as: i) mergers that involve the transfer of shares or the acquisition of part of a firm, ii) mergers with more than two firms and iii) situations where the regulator's ability to control side payments among firms is limited. All of these points are left for future research.

\section{Appendices}

\subsection{Appendix $A$}

Assume we have only one consumer that knows the state of the economy $\bar{\theta}$. Subscript 0 identifies the variables that refer to consumers and subscripts 1 and 2 identify the variables that refer to firms. We construct a mechanism that implements in dominant strategies the efficient merger policy. The space of messages of every player is: $M_{1}=M_{2}=M_{0}=\Theta$. The outcome function is as follows:

$$
\begin{aligned}
h(m) & =\arg \max _{a \in A} C S\left(a, m_{0}\right)+\Pi_{1}\left(a, m_{1}\right)+\Pi_{2}\left(a, m_{2}\right) \\
t_{0}(m) & =\Pi_{1}\left(h(m), m_{1}\right)+\Pi_{2}\left(h(m), m_{2}\right) \\
t_{1}(m) & =C S\left(h(m), m_{0}\right)+\Pi_{2}\left(h(m), m_{2}\right) \\
t_{2}(m) & =C S\left(h(m), m_{0}\right)+\Pi_{1}\left(h(m), m_{1}\right)
\end{aligned}
$$

If agents tell the truth, this mechanism implements the efficient merger policy. It is easy to see that truth is a dominant strategy for every player. For the consumer, this comes from the fact that

$$
\begin{aligned}
& C S\left(h\left(\bar{\theta}, m_{1}, m_{2}\right), \bar{\theta}\right)+\Pi_{1}\left(h\left(\bar{\theta}, m_{1}, m_{2}\right), m_{1}\right)+\Pi_{2}\left(h\left(\bar{\theta}, m_{1}, m_{2}\right), m_{2}\right) \geq \\
& C S\left(h\left(m_{0}^{\prime}, m_{1}, m_{2}\right), \bar{\theta}\right)+\Pi_{1}\left(h\left(m_{0}^{\prime}, m_{1}, m_{2}\right), m_{1}\right)+\Pi_{2}\left(h\left(m_{0}^{\prime}, m_{1}, m_{2}\right), m_{2}\right)
\end{aligned}
$$
for any $m_{0}^{\prime}, m_{1}, m_{2}$. A similar reasoning applies to firms 1 and 2 .

\subsection{Appendix $B$}

Let $\theta^{1}$ and $\theta^{2}$ be such that $\phi^{o}\left(\theta^{1}\right)=a_{1}$ and $\phi^{o}\left(\theta^{2}\right)=a_{2}$. This implies that $\Delta W\left(\theta^{1}\right)>0 \geq \Delta W\left(\theta^{2}\right)$. 
Suppose that $\phi^{o}$ can be implemented in dominant strategies. Then, by the Revelation Principle, there exists a direct mechanism $\left\{\left\{\theta_{i}^{1}, \theta_{i}^{2}\right\}, h(), t_{i}()\right\}_{i=1,2}$ that implements $\phi^{o}$ in Dominant Strategies, where $\theta_{i}^{j}$ denotes the announcement of economy $\theta^{j}$ by firm $i$. Thus, if $\theta^{1}$ is true,

$$
\begin{aligned}
& \Pi_{1}\left(h\left(\theta_{1}^{1}, \theta_{2}^{2}\right), \theta^{1}\right)+t_{1}\left(\theta_{1}^{1}, \theta_{2}^{2}\right) \geq \Pi_{1}\left(h\left(\theta_{1}^{2}, \theta_{2}^{2}\right), \theta^{1}\right)+t_{1}\left(\theta_{1}^{2}, \theta_{2}^{2}\right) \\
& \Pi_{2}\left(h\left(\theta_{1}^{1}, \theta_{2}^{1}\right), \theta^{1}\right)+t_{2}\left(\theta_{1}^{1}, \theta_{2}^{1}\right) \geq \Pi_{2}\left(h\left(\theta_{1}^{1}, \theta_{2}^{2}\right), \theta^{1}\right)+t_{2}\left(\theta_{1}^{1}, \theta_{2}^{2}\right)
\end{aligned}
$$

And if $\theta^{2}$ is true,

$$
\begin{aligned}
& \Pi_{1}\left(h\left(\theta_{1}^{2}, \theta_{2}^{2}\right), \theta^{2}\right)+t_{1}\left(\theta_{1}^{2}, \theta_{2}^{2}\right) \geq \Pi_{1}\left(h\left(\theta_{1}^{1}, \theta_{2}^{2}\right), \theta^{2}\right)+t_{1}\left(\theta_{1}^{1}, \theta_{2}^{2}\right) \\
& \Pi_{2}\left(h\left(\theta_{1}^{1}, \theta_{2}^{2}\right), \theta^{2}\right)+t_{2}\left(\theta_{1}^{1}, \theta_{2}^{2}\right) \geq \Pi_{2}\left(h\left(\theta_{1}^{1}, \theta_{2}^{1}\right), \theta^{2}\right)+t_{2}\left(\theta_{1}^{1}, \theta_{2}^{1}\right)
\end{aligned}
$$

Adding Eqs. (7.1) and (7.3) we have:

$$
\Pi_{1}\left(h\left(\theta_{1}^{1}, \theta_{2}^{2}\right), \theta^{1}\right)+\Pi_{1}\left(h\left(\theta_{1}^{2}, \theta_{2}^{2}\right), \theta^{2}\right) \geq \Pi_{1}\left(h\left(\theta_{1}^{2}, \theta_{2}^{2}\right), \theta^{1}\right)+\Pi_{1}\left(h\left(\theta_{1}^{1}, \theta_{2}^{2}\right), \theta^{2}\right) .
$$

Adding Eqs. (7.2) and (7.4) we have:

$$
\Pi_{2}\left(h\left(\theta_{1}^{1}, \theta_{2}^{1}\right), \theta^{1}\right)+\Pi_{2}\left(h\left(\theta_{1}^{1}, \theta_{2}^{2}\right), \theta^{2}\right) \geq \Pi_{2}\left(h\left(\theta_{1}^{1}, \theta_{2}^{2}\right), \theta^{1}\right)+\Pi_{2}\left(h\left(\theta_{1}^{1}, \theta_{2}^{1}\right), \theta^{2}\right) .
$$

Since the mechanism implements $\phi^{o}$ we have that $h\left(\theta_{1}^{i}, \theta_{2}^{i}\right)=a_{i} i=1,2$ and $\Pi_{2}\left(a_{1}, \theta^{1}\right)=0$. Thus, the previous two equations can be rewritten as follows:

$$
\begin{aligned}
& \Pi_{1}\left(h\left(\theta_{1}^{1}, \theta_{2}^{2}\right), \theta^{1}\right)+\Pi_{1}\left(a_{2}, \theta^{2}\right) \geq \Pi_{1}\left(a_{2}, \theta^{1}\right)+\Pi_{1}\left(h\left(\theta_{1}^{1}, \theta_{2}^{2}\right), \theta^{2}\right) \\
& \Pi_{2}\left(h\left(\theta_{1}^{1}, \theta_{2}^{2}\right), \theta^{2}\right) \geq \Pi_{2}\left(h\left(\theta_{1}^{1}, \theta_{2}^{2}\right), \theta^{1}\right) .
\end{aligned}
$$

If $h\left(\theta_{1}^{1}, \theta_{2}^{2}\right)=a_{1}$, the first equation can be written as:

$$
\Pi_{1}\left(a_{1}, \theta^{1}\right)-\Pi_{1}\left(a_{2}, \theta^{1}\right) \geq \Pi_{1}\left(a_{1}, \theta^{2}\right)-\Pi_{1}\left(a_{2}, \theta^{2}\right)
$$

If $h\left(\theta_{1}^{1}, \theta_{2}^{2}\right)=a_{2}$, the second equation can be written as:

$$
\Pi_{2}\left(a_{2}, \theta^{2}\right) \geq \Pi_{2}\left(a_{2}, \theta^{1}\right) .
$$

Therefore, a necessary condition for implementation is that one of the last two equations holds and they can be written as in Proposition 1 given the definitions introduced in Sect. 3.

\subsection{Appendix $C$}

Profits in monopoly amount to $\pi_{1}=\frac{(a-d)^{2}}{2(1+b)}$. Given that the monopoly sells $x=$ $\frac{a-d}{2(1+b)}$, Social Welfare amounts to $W_{1}=U(x, x)-2 d x=3 \frac{(a-d)^{2}}{(1+b)}=\frac{3}{2} \pi_{1}$.

Profits in duopoly and Cournot competition amount to $\pi_{2 c}=\left(\frac{a-c}{2+b}\right)^{2}$ and Social Welfare to $W_{2 c}=\left(\frac{a-c}{2+b}\right)^{2}(3+b)=(3+b) \pi_{2 c}$.

Profits in duopoly and Bertrand competition amount to $\pi_{2 b}=\left(\frac{1-b}{1+b}\right)\left(\frac{a-c}{2-b}\right)^{2}$ and Social Welfare to $W_{2 b}=\left(\frac{3-2 b}{1+b}\right)\left(\frac{a-c}{2-b}\right)^{2}=\left(\frac{3-2 b}{1-b}\right) \pi_{2 b}$. 
Cournot competition: $\Delta W>0$ iff $\left(\frac{3}{2}\right)\left(P_{1}+P_{2}\right)>P_{2}(3+b)$. Rearranging the last expression we have $P_{1}>P_{2}\left(\frac{3+2 b}{3}\right)$. Thus, in this case $f\left(P_{2}\right)=P_{2}\left(\frac{3+2 b}{3}\right)$

Bertrand competition: $\Delta W>0$ iff $\left(\frac{3}{2}\right)\left(P_{1}+P_{2}\right)>P_{2}\left(\frac{3-2 b}{1-b}\right)$. Rearranging the last expression we have $P_{1}>P_{2}\left(\frac{3-b}{3(1-b)}\right)$. Thus, in this case $f\left(P_{2}\right)=P_{2}\left(\frac{3-b}{3(1-b)}\right)$.

When $a, c$ and $d$ are known and the unknown parameter is $b$, we have for the Cournot case that $\Delta W=\left(\frac{3}{2}\right)\left(P_{1}+P_{2}\right)-P_{2}(3+b)$. Then, using the equation of duopoly profits we may write $b$ as a function of $P_{2}$.

$$
\begin{aligned}
& \Delta W=\left(\frac{3}{2}\right)\left(P_{1}+P_{2}\right)-P_{2}\left(1+\frac{a-c}{\sqrt{P_{2}}}\right) \\
& \Delta W>0 \text { iff } P_{1}>\left(\frac{2}{3}\right)\left((a-c) \sqrt{P_{2}}-\frac{P_{2}}{2}\right)
\end{aligned}
$$

Thus in this case $f\left(P_{2}\right)=\left(\frac{2}{3}\right)\left((a-c) \sqrt{P_{2}}-\frac{P_{2}}{2}\right)$ and $f^{\prime}\left(P_{2}\right)>0$.

\subsection{Appendix $D$}

Assume that firms compete a la Cournot, and market demand, given by $P(X)$, satisfies $P^{\prime}(X)<0$ and

$$
P^{\prime}(X)+P^{\prime \prime}(X) X<0 .
$$

Condition (7.7) guarantees existence and uniqueness of Cournot equilibrium with constant marginal costs. Define $\beta(X) \equiv \frac{P^{\prime \prime}(X) X}{P^{\prime}(X)}$ as the degree of concavity. Then (7.7) can be rewritten as $\beta(X)>-1$. We state the following results concerning a symmetric oligopoly with $n$ firms and constant marginal cost denoted generically by $e$, where $e$ may be either $c$ or $d$. Denote respectively by $X_{n}(e), \pi_{n}(e)$ and $W_{n}(e)$ the output, profits and social welfare in the Cournot equilibrium. $X_{n}(e)$ satisfies the equilibrium condition:

$$
P-e+P^{\prime} \frac{X_{n}(e)}{n}=0
$$

Differentiating (7.8) with respect to $e$ we have:

$$
\begin{aligned}
& P^{\prime}\left(\frac{d X_{n}(e)}{d e}\right)-1+P^{\prime \prime}\left(\frac{d X_{n}(e)}{d e}\right) \frac{X_{n}(e)}{n}+P^{\prime} \frac{\frac{d X_{n}(e)}{d e}}{n}=0 . \text { Thus, } \\
& \frac{d X_{n}(e)}{d e}=\frac{n}{(n+\beta+1) P^{\prime}}
\end{aligned}
$$

Profits in equilibrium satisfy:

$$
\begin{aligned}
\pi_{n}(e) & =-P^{\prime}\left(\frac{X_{n}(e)}{n}\right)^{2} . \text { Thus, } \\
\frac{d \pi_{n}(e)}{d e} & =-\frac{P^{\prime} X_{n}(e) \frac{d X_{n}(e)}{d e}(\beta+2)}{n^{2}}=-\frac{(\beta+2) X_{n}(e)}{n(n+\beta+1)}
\end{aligned}
$$


Social Welfare is $W_{n}(e)=\int_{0}^{X_{n}(e)}(P(x)-e) d x$. Thus,

$$
\frac{d W_{n}(e)}{d e}=(P-e) \frac{d X_{n}(e)}{d e}-X_{n}(e)
$$

Using (7.8) and (7.9), we have that

$$
\frac{d W_{n}(e)}{d e}=-X_{n}(e)\left(\frac{P^{\prime} \frac{d X_{n}(e)}{d e}}{n}+1\right)=-\frac{(n+\beta+2) X_{n}(e)}{(n+\beta+1)}
$$

Merger increases social welfare if $\Delta W=W_{1}(d)-W_{2}(c)>0$. Given that $\pi_{i}(e)$ is invertible we have that $W_{1}\left(\pi_{1}^{-1}\left(\pi_{1}\right)\right)>W_{2}\left(\pi_{2}^{-1}\left(\pi_{2}\right)\right)$. As $\pi_{1}=P_{1}+P_{2}$ and $\pi_{2}=P_{2}, W_{1}\left(\pi_{1}^{-1}\left(P_{1}+P_{2}\right)\right)>W_{2}\left(\pi_{2}^{-1}\left(P_{2}\right)\right)$. As $W_{1}()$ and $\pi_{1}()$ are strictly decreasing we have that $P_{1}>\pi_{1}\left(W_{1}^{-1}\left(W_{2}\left(\pi_{2}^{-1}\left(P_{2}\right)\right)\right)\right)-P_{2}$. So, we take $f\left(P_{2}\right)=$ $\pi_{1}\left(W_{1}^{-1}\left(W_{2}\left(\pi_{2}^{-1}\left(P_{2}\right)\right)\right)\right)-P_{2} .^{7}$

Finally, we check that $f$ is strictly increasing.

$$
\begin{aligned}
f^{\prime}\left(P_{2}\right) & =\left(\frac{\frac{d \pi_{1}\left(W_{1}^{-1}\left(W_{2}\left(\pi_{2}^{-1}\left(P_{2}\right)\right)\right)\right.}{d e}}{\frac{d W_{1}\left(W_{1}^{-1}\left(W_{2}\left(\pi_{2}^{-1}\left(P_{2}\right)\right)\right)\right.}{d e}}\right)\left(\frac{\frac{d W_{2}\left(\pi_{2}^{-1}\left(P_{2}\right)\right)}{d e}}{\frac{d \pi_{2}\left(\pi_{2}^{-1}\left(P_{2}\right)\right)}{d e}}\right)-1 \\
& =2\left(1+\frac{-1}{\left(\beta\left(X_{1}\left(W_{1}^{-1}\left(W_{2}\left(\pi_{2}^{-1}\left(P_{2}\right)\right)\right)\right)\right)+3\right)}\right) \\
& \times\left(1+\frac{2}{\left(\beta\left(X_{2}\left(\pi_{2}^{-1}\left(P_{2}\right)\right)\right)+2\right)}\right)-1>0 .
\end{aligned}
$$

\subsection{Appendix E}

\subsubsection{Cournot competition}

To simplify expressions we use $a \equiv A-c_{1}$ and $d \equiv c_{2}-c_{1}$. The following system gives us $a$ and $d$ as a function of $P_{1}$ and $P_{2}$.

$$
\begin{array}{r}
\left(\frac{a(2-b)-2 d}{4-b^{2}}\right)^{2}=P_{2} \\
\frac{a^{2}}{2(1+b)}-\left(\frac{a(2-b)+b d}{4-b^{2}}\right)^{2}=P_{1}
\end{array}
$$

The only solution when $\mathrm{b}=\frac{1}{2}$ satisfying $a>0$ and $d<\frac{3 a}{4}$ is given by:

$$
a=\sqrt{3\left(P_{2}+4 P_{1}\right)}-\frac{3}{2} \sqrt{P_{2}} \text { and } d=\frac{3}{4} \sqrt{3\left(P_{2}+4 P_{1}\right)}-3 \sqrt{P_{2}} \text {. }
$$

\footnotetext{
7 We can also consider that the buyer is a Stackelberg leader. In the case of linear demand, Assumption
} 1 holds by taking $f\left(P_{a}\right)=3 P_{a}$. 
Using equilibrium outputs the change in welfare can be written as a function of $a$ and $d$ :

$$
\Delta W=\frac{252 a d-27 a^{2}-188 d^{2}}{450} .
$$

Using (7.10), (7.11) can be rewritten as a function of $P_{1}$ and $P_{2}$ :

$$
\Delta W=\frac{6 P_{1}-4 P_{2}-\sqrt{3 P_{2}\left(P_{2}+4 P_{1}\right)}}{4}
$$

This function has two roots $P_{1}=P_{2}\left(\frac{5 \pm 2 \sqrt{3}}{6}\right)$. As $\Delta W$ is convex in $P_{1}$, we have that $\Delta W>0$ if $P_{1}<P_{2}\left(\frac{5-2 \sqrt{3}}{6}\right)$ and $P_{1}>P_{2}\left(\frac{5+2 \sqrt{3}}{6}\right)$. However only the second restriction is compatible with $P_{1}>P_{2}$.

\subsubsection{Bertrand competition}

The following system gives us $a$ and $d$ as a function of $P_{1}$ and $P_{2}$.

$$
\begin{array}{r}
\left(\frac{a\left(2-b-b^{2}\right)-\left(2-b^{2}\right) d}{\left(4-b^{2}\right)\left(4-5 b^{2}+b^{4}\right)}\right)^{2}=P_{2} \\
\frac{a^{2}}{2(1+b)}-\left(\frac{a\left(2-b-b^{2}\right)+b d}{\left(4-b^{2}\right)\left(4-5 b^{2}+b^{4}\right)}\right)^{2}=P_{1}
\end{array}
$$

The only solution when $\mathrm{b}=\frac{1}{2}$ satisfying $a>0$ and $d<\frac{5 a}{7}$ is given by:

$$
\begin{aligned}
& a=\frac{7 \sqrt{39 P_{1}+4 P_{2}}-36 \sqrt{P_{2}}}{13} \\
& d=\frac{10 \sqrt{39 P_{1}+4 P_{2}}-45 \sqrt{3 P_{2}}}{26}
\end{aligned}
$$

Using equilibrium outputs the change in welfare can be written as a function of $a$ and $d$ :

$$
\Delta W=\frac{800 a d-125 a^{2}-632 d^{2}}{1350}
$$

Using (7.12) and (7.13), (7.14) can be rewritten as a function of $P_{1}$ and $P_{2}$ :

$$
\Delta W=\frac{351 P_{1}-434 P_{2}-48 \sqrt{P_{2}\left(4 P_{2}+13 P_{1}\right)}}{338}
$$

This function has two roots $P_{1}=P_{2}\left(\frac{2(55 \pm 8 \sqrt{10})}{81}\right)$. As the function is convex in $P_{1}$, we have that $\Delta W>0$ if $P_{1}<P_{2}\left(\frac{2(55-8 \sqrt{10})}{81}\right)$ and $P_{1}>P_{2}\left(\frac{2(55+8 \sqrt{10})}{81}\right)$. However only the second restriction is compatible with $P_{1}>P_{2}$. 


\section{References}

Besanko D, Spulber DF (1993) Contested mergers and equilibrium antitrust policy. The Journal of Law, Economics \& Organization 9(1): 1-29

Clarke E (1971) Multipart pricing of public goods. Public Choice 8: 19-33

Dasgupta P, Maskin E (2000) Efficient auctions. The Quarterly Journal of Economics CXV: 341-388

Deneckere R, Davidson C (1985) Incentives to form coalitions with Bertrand competition. Rand Journal of Economics 16: 473-486

Department of Justice and the Federal Trade Commission (1997) Merger guidelines. Issued 1992, revised in April 1997

Farrell J, Shapiro C (1990) Horizontal mergers: an equilibrium analysis. American Economic Review March: 107-126

Fudenberg D, Tirole J (1991) Game theory. MIT Press, Cambridge, MA

Green J, Laffont JJ (1979) Incentives in Public Decision Making. North Holland, Amsterdam

Groves T (1973) Incentives in teams. Econometrica 41: 617-631

Jackson M (2001) A crash course on implementation theory. Social Choice and Welfare 18(4): 655-708

Jehiel P, Moldovanu B (2001) Efficient design with interdependent valuations. Econometrica 69(5): $1237-1259$

Levin D (1990) Horizontal mergers: the 50-percent benchmark. American Economic Review 80(5): $1238-1245$

Moore J, Repullo R (1988) Subgame perfect implementation. Econometrica 56: 1191-1220

Moore J, Repullo R (1990) Nash implementation: a full characterization. Econometrica 58: 1083-1099

Perry M, Porter R (1986) Oligopoly and the incentive for horizontal merger. American Economic Review 75(1): 219-227

Salant S, Switzer S, Reynolds R (1983) Losses from horizontal mergers. Quarterly Journal of Economics 98(2): 185-199

Salinger MA (1988) Vertical mergers and market foreclosure. Quarterly Journal of Economics 103(2): 345-356

Salop S, et al. (1987) Symposium on mergers and antitrust. Journal of Economic Perspectives 1: 3-54

Shapiro C (1995) Merger with Differentiated Products. Conference given before the American Bar Association International Bar Association. Washington, DC, November 9

Singh V, Vives X (1984) Price and quantity competition in a differentiated duopoly. Rand Journal of Economics 15: 546-554

Vickers J (1995) Competition and regulation in vertically related markets. Review of Economic Studies 62: $1-17$

Vickrey W (1961) Counterspeculation, auctions and competitive sealed tenders. Journal of Finance 16: $8-37$

Werden GJ (1996) Simulating the Effects of Differentiated Products Mergers. U.S. Department of Justice Working Paper, June 24, EAG 96-2

Williamson O (1968) Economies as an antitrust defence: the welfare tradeoffs. American Economic Review 58: 18-36 